\title{
Modeling of Vertical Transport of Hydrocarbons of Crude Oil Spills in Non-Convective Water Bodies Supported by Suspended Sediments: Case of Parts of the Nigerian Niger Delta Mangrove Swamps
}

\author{
Teddy Odisu ${ }^{1 \star}$, Charity Okieimen ${ }^{2}$, Samuel Ogbeide ${ }^{2}$
}

${ }^{1}$ Department of Chemical Engineering, Federal University of Petroleum Resources, Effurun, NIGERIA

${ }^{2}$ Department of Chemical Engineering, University of Benin, Benin-City, NIGERIA

*Corresponding Author: teddyodi2002@yahoo.com

Citation: Odisu, T., Okieimen, C. and Ogbeide, S. (2020). Modeling of Vertical Transport of Hydrocarbons of Crude Oil Spills in Non-Convective Water Bodies Supported by Suspended Sediments: Case of Parts of the Nigerian Niger Delta Mangrove Swamps. European Journal of Sustainable Development Research, 4(4), em0143. https://doi.org/10.29333/ejosdr/9144

\section{ARTICLE INFO}

Received: 18 May 2020

Accepted: 5 Aug. 2020

\begin{abstract}
Crude oil spill is a major source of water pollution. In water with wave and tides, the environment could be selfcleansed. This kind of environment has enjoyed tremendous research attention over the years with plethora of models available for the forecasting, monitoring and management of residual petroleum presence in imparted environments. On the other hand, parts of the Nigerian Niger Delta mangrove swamp contain stagnant water with suspended sediments. The heavy load of suspended sediments has the capacity to adsorb oil and dissolved hydrocarbon components. This paper reports on the development of models for the vertical transport and concentrations of petroleum hydrocarbon components at different strata of the water column by suspended sediments adsorption using governing equations of transport and mass transfer. The developed models were validated with data obtained from simulated stagnant water that was polluted with crude oil.
\end{abstract}

Keywords: crude oil spill, hydrocarbons, Mangrove Swamp, models, sediments

\section{INTRODUCTION}

Over the years, several efforts have been made to effectively review existing information on oil spill transport mechanisms as well as development of predictive mathematical models for water bodies (Giwa and Jimoh, 2010; Jimoh and Alhassan, 2006; Njobuenwu and Abowei, 2008; Njobuenwu, 2014; Susu et al., 1997). These efforts have enhanced the practice and helped in the identification of available knowledge gaps oil spill management and research (Chao et al., 2001; Garcia-Martinez and Flores-Tovar, 1999; Lonin, 1999; Tkalich, 2006; Wang et al., 2005). One of such knowledge gaps is the low research attention in oil spill transport mechanism in non-turbulent water bodies (stagnant water) as found in some parts of the Niger Delta region of Nigeria and more importantly, the role of suspended sediments resulting from dead vegetation in the transport of whole oil and hydrocarbon components after an oil spill. The need for a shift in attention or focus is borne out of a careful observation of the existing oil spill models which show that a majority of them are focused on horizontal distribution of whole oil, weathering and the general fate of spilled oil in rivers and seas that are characterized by flow, high turbulence and effect of wind (Bragg and Owen, 1995; Le Floch et al., 2002; Owens and Lee, 2003; Owens et al., 2003; Page et al., 2000). Even in occasions where the vertical transport trajectories were considered, the focus was on particulate transport occasioned by the breaking of the oil slick into oil particles by waves that could be stabilized by the presence of suspended sediments, which, depending on density difference with the water, begin to sink and even re-suspend (Boufadel et al., 2020; Imanian et al., 2017; Li et al., 2018; Röhrs et al., 2018, 2019).

This gap has led to a dearth of information both in practical modeling approach and empirical data availability on the transport and behavior of spilled oil in non-flowing water bodies particularly mangrove swamps with relatively static water and the role of suspended sediments that are in the water arising from decaying vegetation as can be found in some parts of the oil rich Niger Delta region of Nigeria (Odisu, 2020; Odisu et al., 2020).

Directing attention to the Nigerian Niger Delta region has become extremely important because parts of its swamps contain water bodies with very low or even no observable flow and laden with heavy load of suspended sediments and vegetation. Also, the region experience high level of crude oil exploration, production and transportation activities leading to accidental and deliberate oil spill with attendant environmental consequences.

Odisu et al. (2020) has shown that in the event of an oil spill in this kind of aquatic environment, the transport and overall fate will be totally different from what is obtained for open water with wave and wind. The research also showed that besides diffusion 


\section{Control volume}

$\mathrm{T}=0$

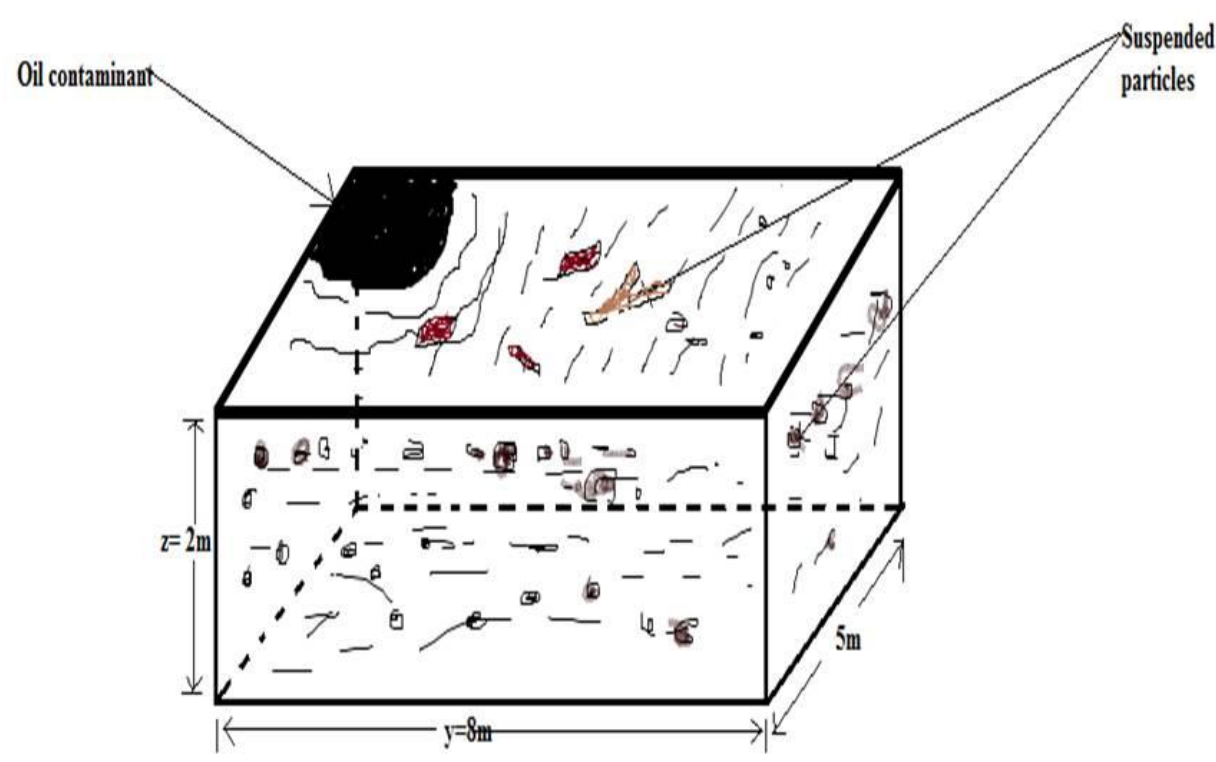

Figure 1. Initial situation of the pond on contamination

of dissolving petroleum hydrocarbon components through the bulk of the water, their transport will also be supported by the simple principle of dissolved oil components- sediment partitioning. This therefore makes existing models un-amenable to cases of relatively static water bodies in these parts of the Nigerian Niger Delta mangrove swamps.

This paper reports the application of the fundamental governing equations of transport and mass transfer in modeling the transport of whole oil and dissolved components supported by suspended sediment in a stagnant water body with consideration to adsorption of whole oil onto sediment, dissolution of petroleum hydrocarbon components from the oil slick into the water-oil interface, diffusion of dissolved components through water, adsorption of a fraction of the diffusing components by suspended sediments which may lead to sinking and sedimentation or trapping within the water column depending on density difference.

The reliability of the model developed was verified using data from a simulated oil spill site typical of parts of the Niger Delta mangrove swamp with static water and monitored for ten (10) months. The result obtained were analyzed including calculation of the $\mathrm{R}^{2}$ values case by case. Results obtained are as shown in the result section.

\section{MODEL DEVELOPMENT}

The model development was based on a stagnant water body system with suspended sediments as a result of dead vegetation as shown in the schematics in Figures 1 to 4.

The general conservation equation expressed in Equation 1 and based on Figure 4 serve as the basis for the mathematical description of the transport of hydrocarbon component from the oil sleek on the surface (bulk) into the oil water interface and then the water column.

$$
\begin{gathered}
\text { Rate of acumulation } \\
\left(\begin{array}{c}
\text { of dissolved aliphatic or aromatic hydrocarbons }
\end{array}\right) \\
=\text { Amount in }- \text { Amount out }+ \text { net amount introduced by source }
\end{gathered}
$$

Identifying the mass flux as a summation of both the convective and diffusive fluxes, Equation 1 is then expressed as;

(Rate of accumulation of aliphatic or aromatic hydrocarbons in the water column)

$=($ Net inflow rate of aliphatics or aromatics by convection $)$

+ (Net inflow rate of aliphatics or aromatics by diffusion)

+ (Net source of aliphatics or aromatics by dissolution from oil bulk

+ Net source of aliphatics or aromatics by biodegradation) 


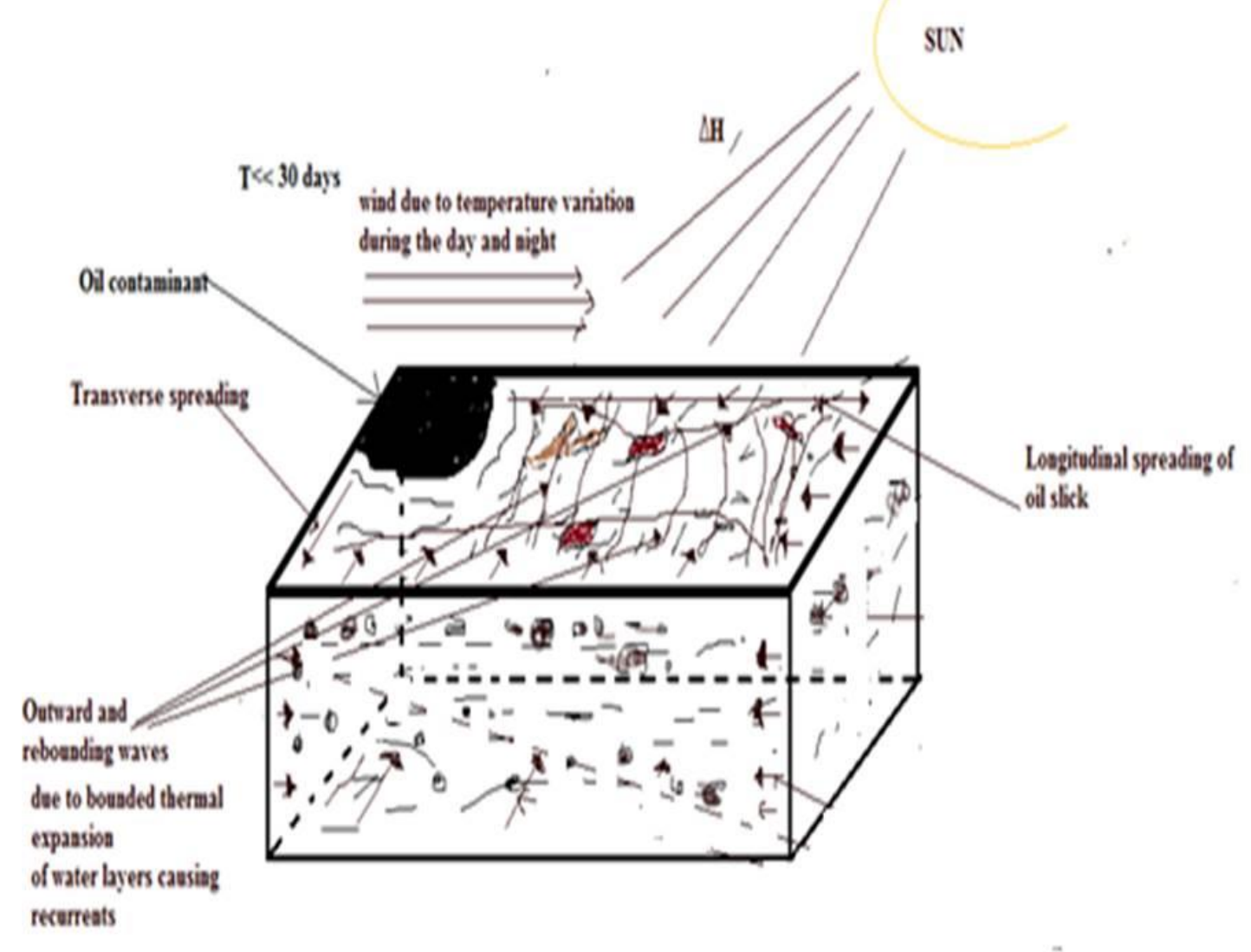

Figure 2. Spread of the oil layer

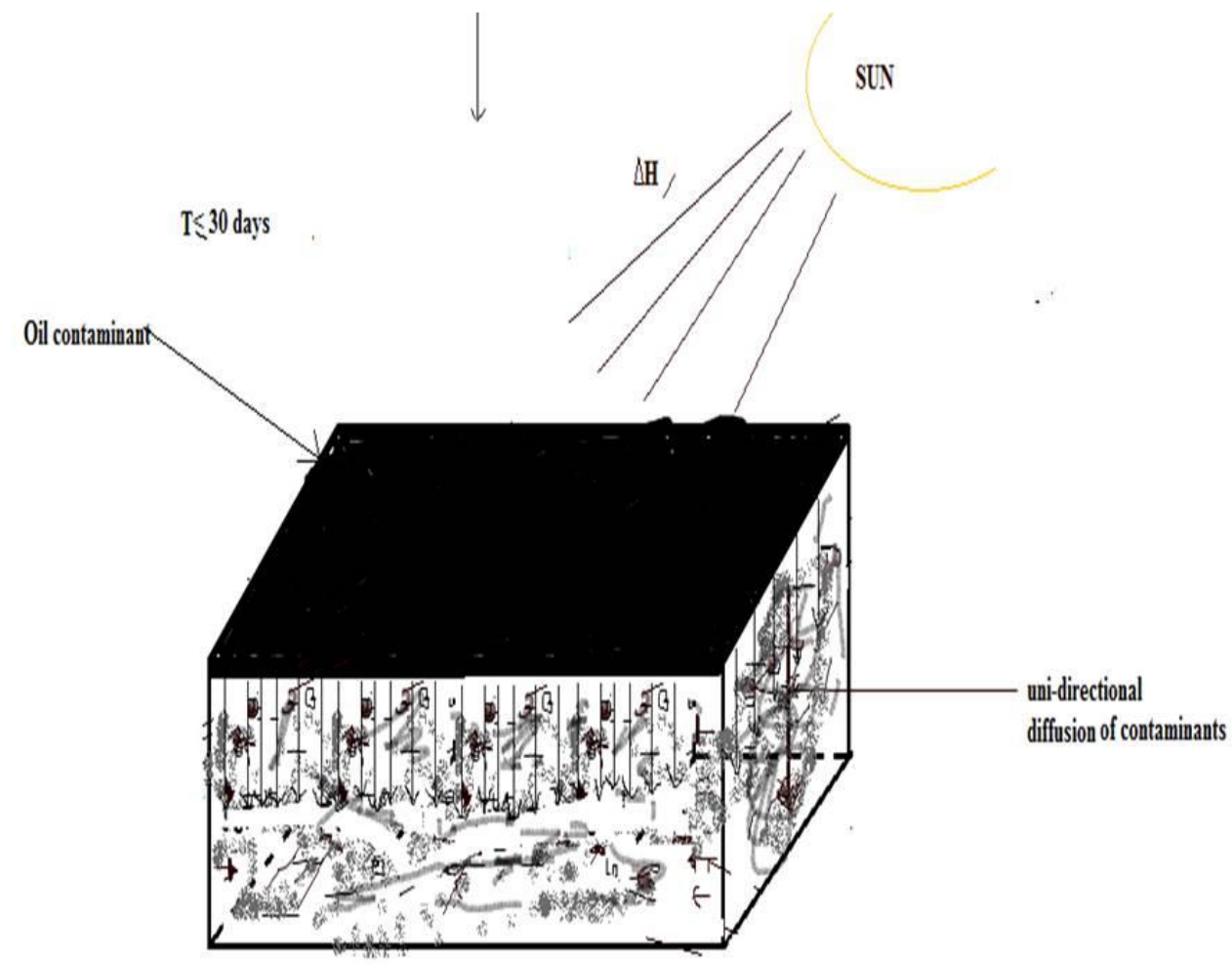

Figure 3. Slick covered water body 


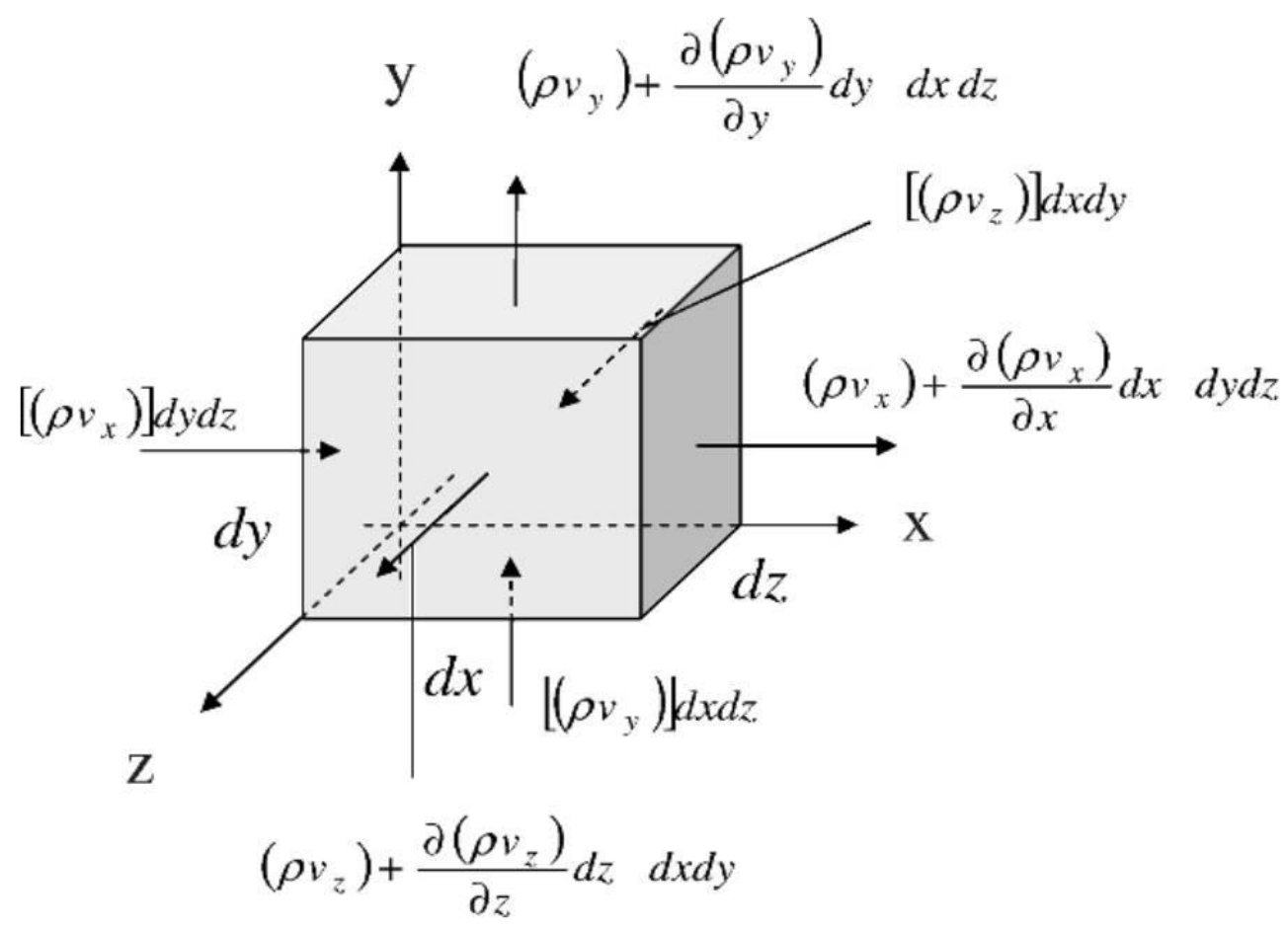

Figure 4. Schematics showing the mass transfer in a control volume fixed in space showing both the convective and diffusive mass fluxes through the various faces of the volume element used as basis for the model derivation

Consideration is here given to the conservation law of the quantity $\psi$ within the fixed macroscopic volume $V$ bounded by the fixed macroscopic surface area $A$ as expressed in Equation (3).

$$
\frac{\delta}{\delta t}=\rho \psi d v=-\int_{A}\left(\rho v \Psi \cdot n d a-\int_{A}^{\cdot} J \cdot n d a+\int_{V} \Phi d v\right.
$$

The convective and diffusive transport terms can be rewritten as a volume integral using Gauss' theorem and the Equation can then be assembled in a single volume integral:

$$
\begin{aligned}
& \int_{V}\left(\frac{\delta(\rho v)}{\delta t}+\nabla \cdot(\rho v \psi+\nabla \cdot J)-\Phi\right) \\
& \left.\frac{\partial(\rho \psi)}{\delta t}+\nabla \cdot(\rho v \Psi)+\nabla \cdot J\right)-\Phi=0
\end{aligned}
$$

For the peculiarity of this work, we assume that the convective transport term or convective flux reduces to zero, that is there is no transport due to convection or bulk flow because the water body under consideration is a relatively stagnant one. The Equation will therefore reduce to the form

$$
\frac{\partial(\rho \psi)}{\delta t}+\nabla(\nabla . J-\Phi)=0
$$

As mentioned earlier, the source term is a contribution from the dissolution of hydrocarbon (aliphatics and aromatics) from the bulk (oil sleek), and the biodegradation of the hydrocarbons by microbial activities. Equation (5) can also be represented as Equation (7)

$$
\frac{\partial c}{\partial t}=D \frac{\partial^{2} c}{\partial x^{2}}-\Phi
$$

The hydrocarbon supply into the water -oil interface is represented as

$$
\frac{d m}{d t}=A \frac{D}{d}\left(c_{s}-c_{t}\right)
$$

The biodegradation of dissolved hydrocarbon process could be represented by a multi-substrate Monod model where multiple growth substrates are available to oil degrading microbes. 
However, Vilcaez et al. (2013) in attempt to formulate the theoretical work first tried both multi-substrate and sole-substrate models for the degradation of soluble oil. They reported that the outcome for both sole and multiple substrate models were very close. Therefore, because the kinetic coefficients for sole-substrate models are typically more available from total petroleum hydrocarbons (TPH) biodegradation measurements or oxygen uptake measurements than those for multi-substrate models, for simplicity, the sole-substrate model is used for all hydrocarbons pseudo-components as shown in Equations (9), (10) and (11).

$$
\begin{gathered}
r_{b=\mu_{\max }} \frac{c}{k_{s}+c} B \\
r=\frac{1}{Y} r_{b}
\end{gathered}
$$

Therefore,

$$
r=\frac{1}{Y} \mu_{\max } \frac{c}{k_{s}+c} B
$$

A distinguishing feature in this model will be the application of species transport. Since it is the individual hydrocarbon that diffuse through the water body, it will be of good that the model is further broken down to account for the transport of each hydrocarbon specie mass as a contribution to the bulk mass transport equation above.

It has been established that individual chemical species $\mathrm{c}$ in a mixture moves at their different velocities denoted by $\mathbf{v}_{c}$ with respect to stationary coordinate axis. Thus, for a mixture of $N$ number of species, the local mass-average velocity $\mathbf{v}$ is defined as

$$
\begin{gathered}
v=\frac{\sum_{c=1}^{N} \rho_{c} v_{c}}{\sum_{c=1}^{N} \rho_{c}}=\frac{\sum_{c=1}^{N} \rho_{c} v_{c}}{\rho}=\sum_{c=1}^{N} w_{c} v_{c} \\
w_{c}=\frac{\rho_{c}}{\rho}
\end{gathered}
$$

and the species mass density relates to the known molar concentration

$$
C_{c}=\frac{\rho_{c}}{M_{w c}}
$$

And the mole fraction is

$$
x_{c}=\frac{C_{c}}{C}
$$

The next factor is the diffusion velocity which is the motion of component $c$ relative to the local motion of the mixture stream represented as

$$
v_{c, d}=v_{c}-v
$$

Next is the mass flux of species $c$, a vector quantity which denotes the mass of species $c$ that passes through a unit area per unit time. The mass flux relative to stationary coordinates is defined by:

$$
m_{c}=\rho_{c} v_{c}
$$

Thus, the relative mass flux or diffusive mass is defined as

$$
J_{C}=\rho_{C}\left(v_{c}-v\right)=\rho_{c} v_{c, d}
$$

where $J_{c}$ is approximated for binary mixtures by Fick's law to be

$$
J_{c}=-\rho D_{c} \nabla w_{c}
$$

The minus sign accounts for the mass flux of species $\mathrm{c}$ in the direction of decreasing concentration

$$
J_{c}=J_{c}^{o}+J_{c}^{p}+J_{c}^{g}+J_{c}^{T}=\rho_{c} v_{c, d}
$$

However, as stated earlier, the convective flux term is assumed to be zero making the system static. As such, the available flux will be principally due to diffusion.

It is also to be noted that the transport of hydrocarbons into the bulk of the water is principally through diffusive mass transfer with a proportion of the diffusing hydrocarbon getting adsorbed by suspended sediments that are available all around the water column.

Therefore, from Equation 6,

$$
\nabla(\nabla . J) \text { can be represented as } \nabla(\nabla . J)_{\text {water }}+\nabla(\nabla . J)_{\text {sediment }}
$$




$$
\begin{gathered}
\text { Where } \nabla(\nabla . J)_{\text {sediment }}=\frac{\delta q_{i}}{\delta t}=K_{L, i}\left(q^{*}{ }_{i}-q_{i}\right) \\
\frac{\partial(\rho \psi}{d t}=-\nabla(\nabla . J)+\left(\frac{d m}{d t}-r_{\text {oil }}\right)
\end{gathered}
$$

It therefore implies that for situations when the model seeks to establish the total hydrocarbon availability in sediment alone, $\nabla(\nabla . J)_{\text {water }}$ reduces to zero,

$$
\frac{\partial(\rho \psi}{d t}=-\nabla(\nabla . J) \text { sediment }+\left(\frac{d m}{d t}-r_{o i l}\right)
$$

For total aliphatic hydrocarbon in sediment, we have

$$
\frac{\partial c_{A l i}}{d t}=-\nabla(\nabla . J) \text { sediment }+\left(\frac{d m}{d t}-r_{a l i}\right)
$$

While for total aromatic hydrocarbons in sediment

$$
\frac{\partial c_{\text {Aro }}}{d t}=-\nabla(\nabla . J) \text { sediment }+\left(\frac{d m}{d t}-r_{\text {aro }}\right)
$$

While the above three Equations are for total aliphatic and aromatic hydrocarbons, they can also be used to represent individual aliphatics and aromatics like n-octane, pristane, naphthalene and anthracene. Thus,

$$
\begin{gathered}
\frac{\partial c}{\partial t}=k_{a d}\left(q^{*}-q_{t}\right)+k_{d i s}\left(c_{s}-c_{t}\right)-r_{\text {oil }} \\
\frac{\partial c(\text { ali })}{\partial t}=k_{a d(a l i)}\left(q_{(\text {ali })}{ }^{*}-q_{t(\text { ali })}\right)+k_{\text {dis (ali) })}\left(c_{s(\text { ali })}-c_{t(\text { ali })}\right)-\left(k_{\text {bio-w (ali) }} c_{(\text {ali })}+k_{\text {bio-sed (ali })}\right) \\
\frac{\partial c(\text { aro })}{\partial t}=k_{\text {ad (aro) }}\left(q_{(\text {aro })}{ }^{*}-q_{t(\text { aro })}\right)+k_{\text {dis (aro })}\left(c_{s(\text { aro })}-c_{t(\text { aro })}\right)-\left(k_{\text {bio-w (aro })} c_{(\text {aro })}+k_{\text {bio-sed (aro })}\right)
\end{gathered}
$$

From Equation (5),

$$
\begin{aligned}
& \frac{\partial(\rho \psi}{d t}=-(\nabla(\nabla . J) \text { water }+\nabla(\nabla . J) \text { sediment })+\left(\frac{d m}{d t}-r_{\text {oil }}\right) \\
& \frac{\partial c(a l i)}{\partial t}=D_{a l i} \frac{\partial^{2} c_{a l i}}{\partial x^{2}}+k_{a d(a l i)}\left(q_{(a l i)}{ }^{*}-q_{t(a l i)}\right)+k_{d i s(a l i)}\left(c_{s(a l i)}-c_{t(a l i)}\right)-\left(k_{b i o-w(a l i)} c_{(a l i)}\right. \\
& \left.+k_{\text {bio-sed (ali) }}\right) \\
& \begin{array}{c}
\frac{\partial c(\text { aro })}{\partial t}=D_{\text {aro }} \frac{\partial^{2} c_{\text {aro }}}{\partial x^{2}}+k_{\text {ad (aro })}\left(q_{(\text {aro })}{ }^{*}-q_{t(\text { aro })}\right)+k_{\text {dis (aro })}\left(c_{s(\text { aro })}-c_{t(\text { aro })}\right)-\left(k_{\text {bio }-w(\text { aro })} c_{(\text {aro })}\right) \\
\left.+k_{\text {bio-sed (aro })}\right)
\end{array} \\
& \text { Recall that } C_{Z T=} C_{w}+C_{s e d} \\
& C_{w}=D \frac{\partial^{2} c}{\partial z^{2}}-k_{s}\left(q^{*}-q_{t}\right)+k_{d}\left(c_{s}-c_{t}\right)-k_{b i o} c
\end{aligned}
$$

and $C_{\text {sed }}=C_{Z T}-C_{w}$

Hai-Long et al. (2011), developed partial differential equations to represent each of these model components as shown by Equation (29) to (32)

$$
\begin{gathered}
D \frac{\partial^{2} c}{\partial z^{2}}=\frac{\partial A h c}{\partial t}+\frac{\partial c}{\partial z}=\frac{\partial}{\partial z}\left(A h D_{z} \frac{\partial c}{\partial z}\right) \\
k_{a d}\left(q^{*}-q_{t}\right)=\frac{\partial A h C_{s}}{\partial t}+\frac{\partial C_{s}}{\partial z}+P_{w} \frac{w_{s}}{h} A h C_{s}-P_{r} \frac{\epsilon}{h} A h C_{s} \\
=\frac{\partial}{\partial z}\left(A h D_{z} \frac{\partial C_{s}}{\partial z}\right)+K_{s} K_{p} A h \theta C_{d}-K_{p} A h \theta C_{d}-K_{b} A h C_{s} \\
\boldsymbol{k}_{\text {dis }}\left(\boldsymbol{c}_{\boldsymbol{s}}-\boldsymbol{c}_{\boldsymbol{t}}\right)=+\frac{\partial C_{d}}{\partial z}=\frac{\partial}{\partial z}\left(A h D_{z} \frac{\partial C_{d}}{\partial z}\right)+K_{d i s} K_{P} A h C_{d i s}-K_{b i o} A h C_{d}
\end{gathered}
$$

\section{METHOD OF SOLUTION}

In solving the model, the following pathway was followed as shown in the flow chart below: 


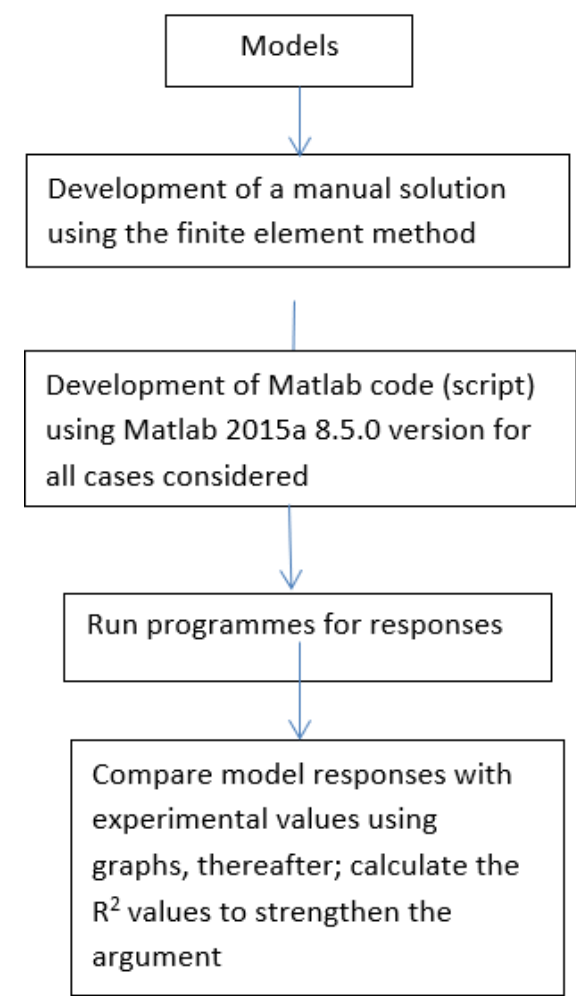

The method of solution based on the above flow chart involves a development of a manual solution of the model using the manual finite element method and then a Matlab program was developed. The essence of the Matlab is to automate the process, increase the accuracy and post processing of solutions in terms of graphs. In the manual solution only six (6) elements were used for discretization whereas over a hundred (100) were used in the Matlab solution. This also applied to the time step.

The manual finite element solution involves the following steps

- Discretization of the domain into a collection of preselected finite elements

- Selection of the element equations for all typical elements in the mesh, element interpolation function and then the element matrices was computed

- Assembly of the equations to obtain the equations of the whole problem

- Imposition of the boundary conditions of the problem

- Solving the assembled equations

While the Matlab program development involved the following steps

- Specification of the constants and initial boundary conditions

- Generating the interpolation function (shape function)

- Carrying out integration and obtaining the coefficient matrix for F,M and $\mathrm{K}$

- Substitution of constants and domain values into the coefficient matrix generated

- Assembling the matrix and varying out row reduction based on boundary condition

- Using alpha family of approximations, the equations were solved applying iterative approach

- Finally, tabulating the solution for each iteration and plotting the graphs

\section{MODEL RESULT}

\section{Model Validation}

The models (Equations 27 and 28) developed and their response patterns were tested using data obtained from a simulated oil spill. The spill site was prepared by spilling 60 litres of crude oil sourced from a flow station in Delta State, Nigeria with viscosity of $13.5 \mathrm{cp}$ on a simulated mangrove swamp of $8 \mathrm{~m}$ long, $5 \mathrm{~m}$ wide and $1.5 \mathrm{~m}$ deep typical of parts of the Niger Delta region of Nigeria. The volume used was such that could cover the entire surface uniformly. Samples were then collected using an improvised depth sampler after every 30 days for a period of 10 months at depths of $0.25 \mathrm{~m}, 0.5 \mathrm{~m}, 0.75 \mathrm{~m}$ and $1.0 \mathrm{~m}$. Details of the experiment and procedure have been well documented by Odisu et al. (2020) and Odisu (2020). The validity was further strengthened by calculating the $\mathrm{R}^{2}$ case by case.

Figures 5 to 9 show the experimental result matched with the model result for the transport of aliphatics adsorbed by sediments alone for the first 5 months. 


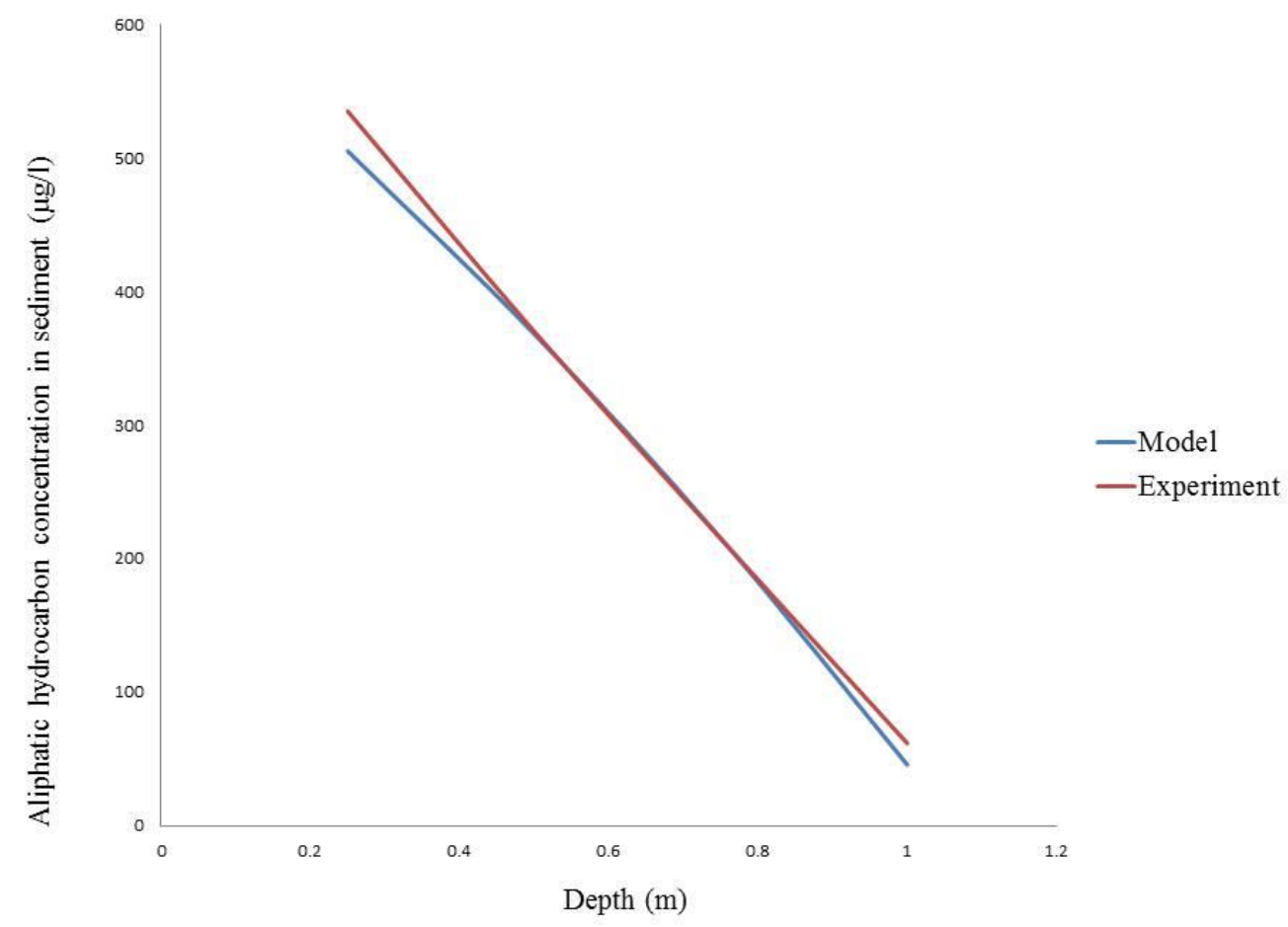

Figure 5. Total aliphatic transport by sediment adsorption for varying depth and fixed time of one month for experiment and model

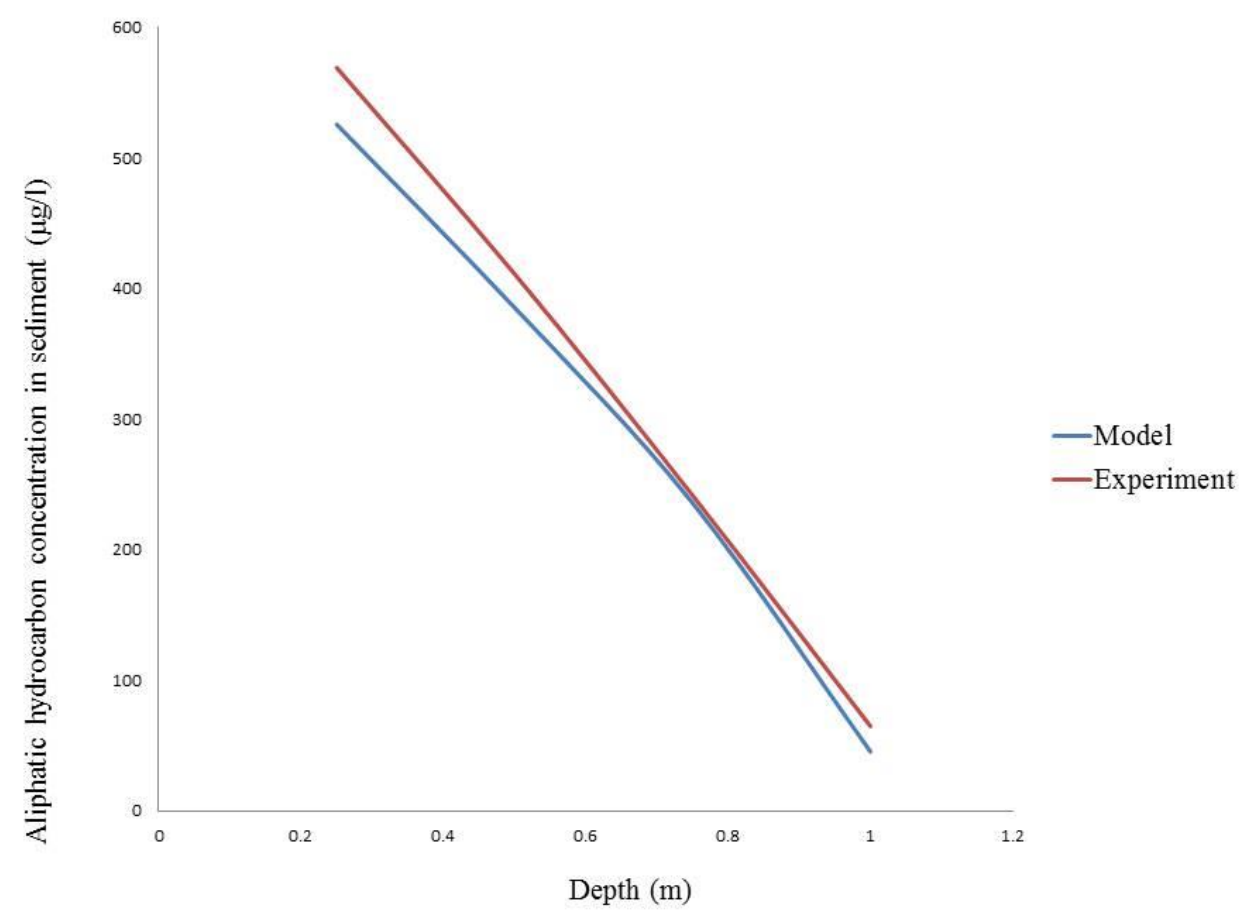

Figure 6. Total aliphatic transport by sediment adsorption for varying depth and fixed time of two months for experiment and model 


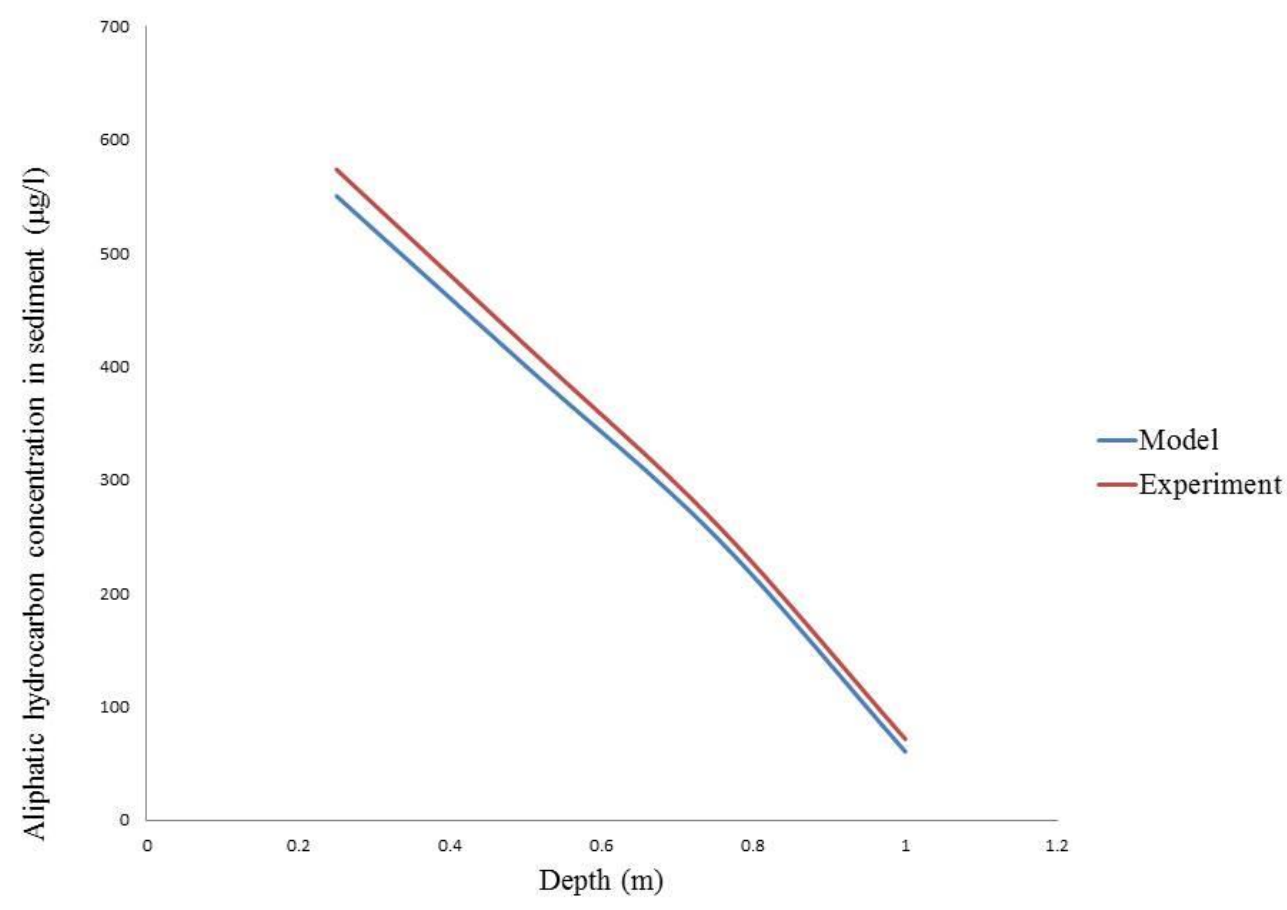

Figure 7. Aliphatic transport by sediment adsorption for varying depth and fixed time of three months for experiment and model

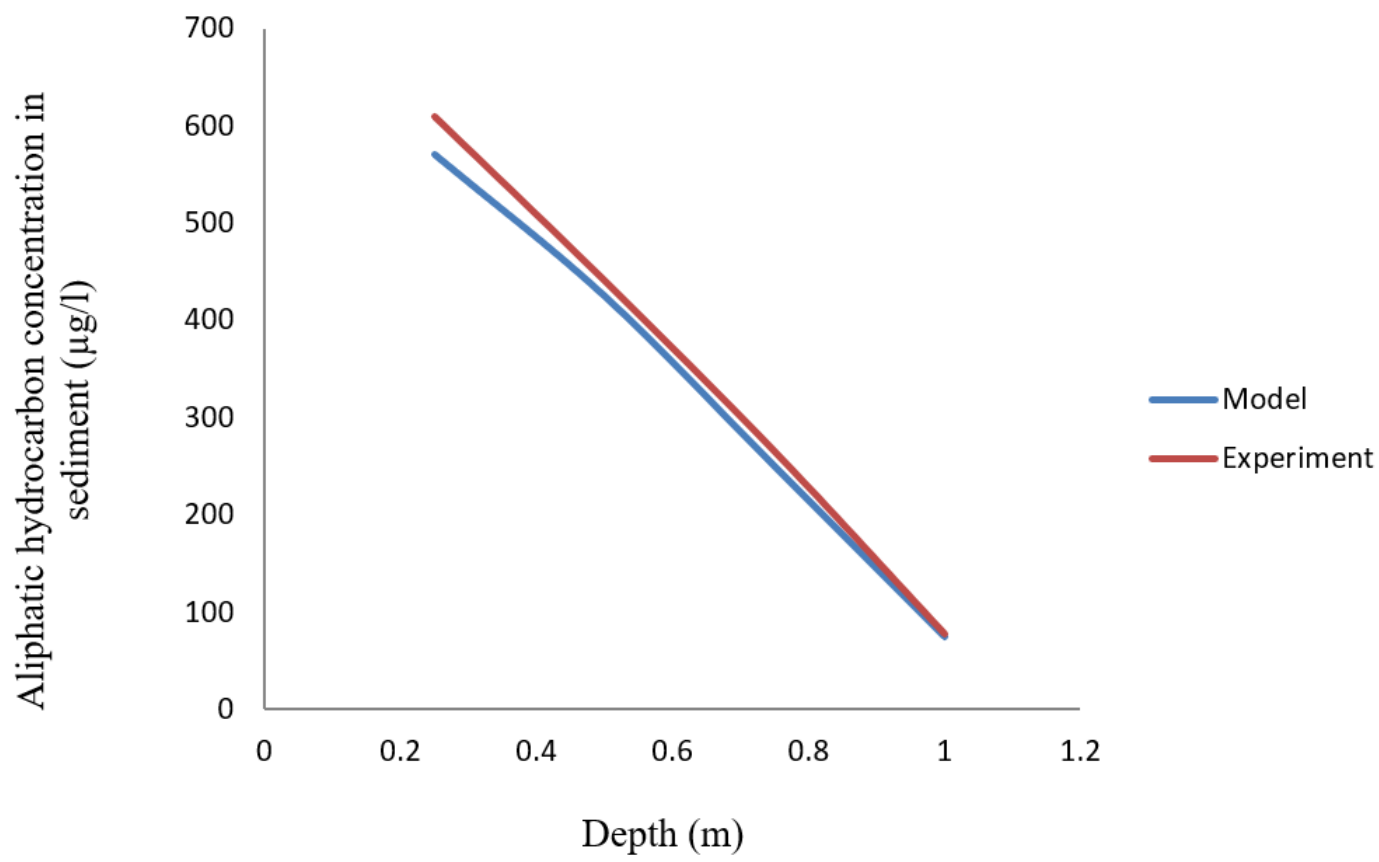

Figure 8. Aliphatic transport by sediment adsorption for varying depth and fixed time of four months for experiment and model 


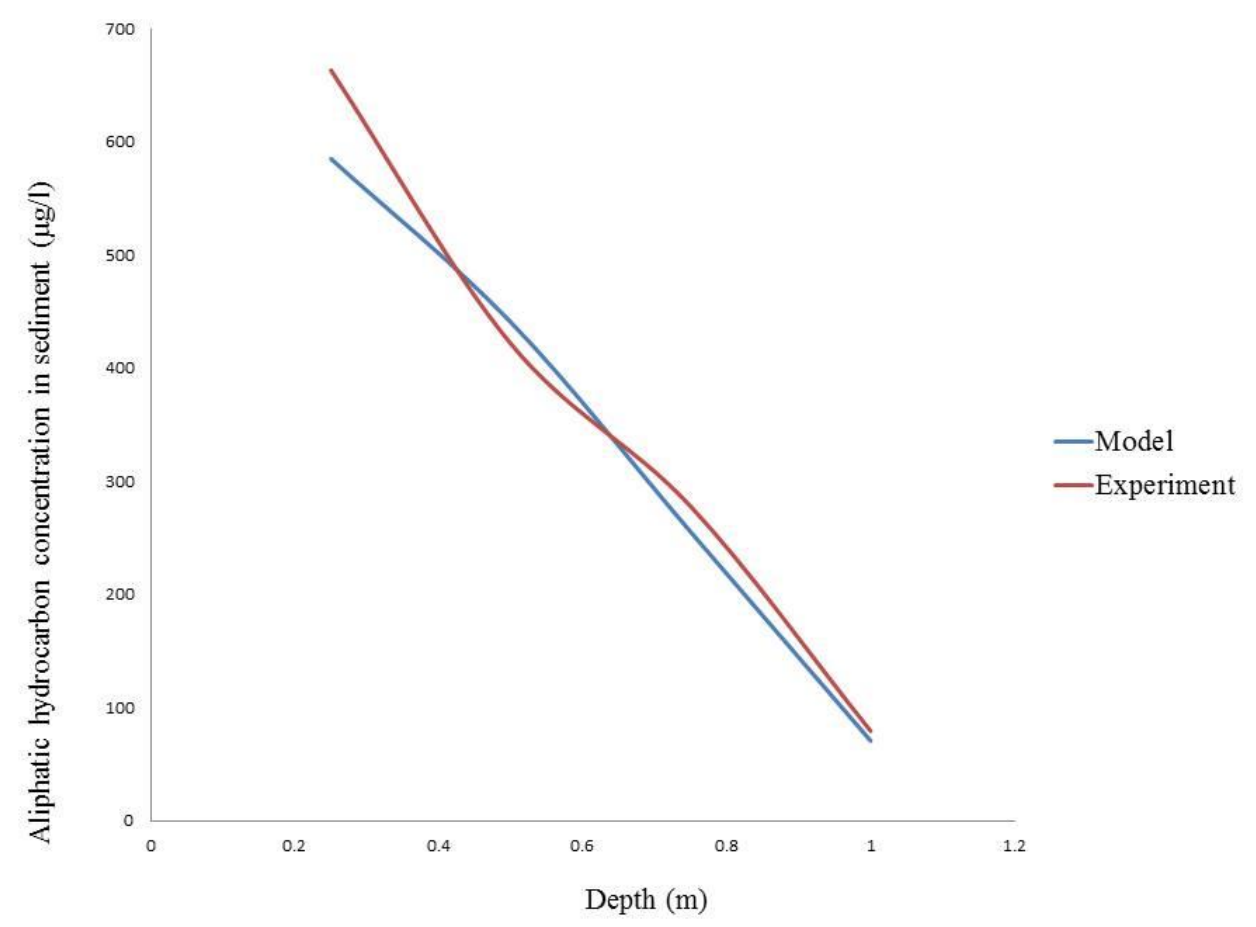

Figure 9. Aliphatic transport by sediment adsorption for varying depth and fixed time of five months for experiment and model

Figures 5 to 9 show the plots for aliphatic hydrocarbon concentration occasioned by suspended sediments transport from top to bottom of the water column for the experimental and predicted (model) for months one to five (others not shown here). The plots of month one to five at depth $0.25 \mathrm{~m}$ to $1.0 \mathrm{~m}$ show a good reflection of the experimental plots by the model plots. There was basically no case of remarkable departure. Also, the calculated $R^{2}$ using the model responses and the experimental result for the aliphatic concentration distribution by sediment transport at depths of $0.25 \mathrm{~m}, 0.5 \mathrm{~m}, 0.75 \mathrm{~m}$ and $1.0 \mathrm{~m}$ were $0.78,0.81,0.71$ and 0.72 respectively. The $\mathrm{R}^{2}$ values obtained are observed to be lower than those obtained for the case of aromatic hydrocarbon transport as reported in the aromatic section below. This may be as a result of assumptions and constants adopted which seem to have favored the aromatic transport better that the aliphatics. Nonetheless, they still fall within the regime of acceptable correlation values. Thus, it can be safely implied that the model developed has the capacity to give a good prediction of the aliphatic hydrocarbon transport by suspended sediment along the water column of a calm water body situated in a mangrove swamp.

Figures 10 to 14 show the result of model and experimental match for first months for aromatic hydrocarbon transport by sediment adsorption across the water column. 


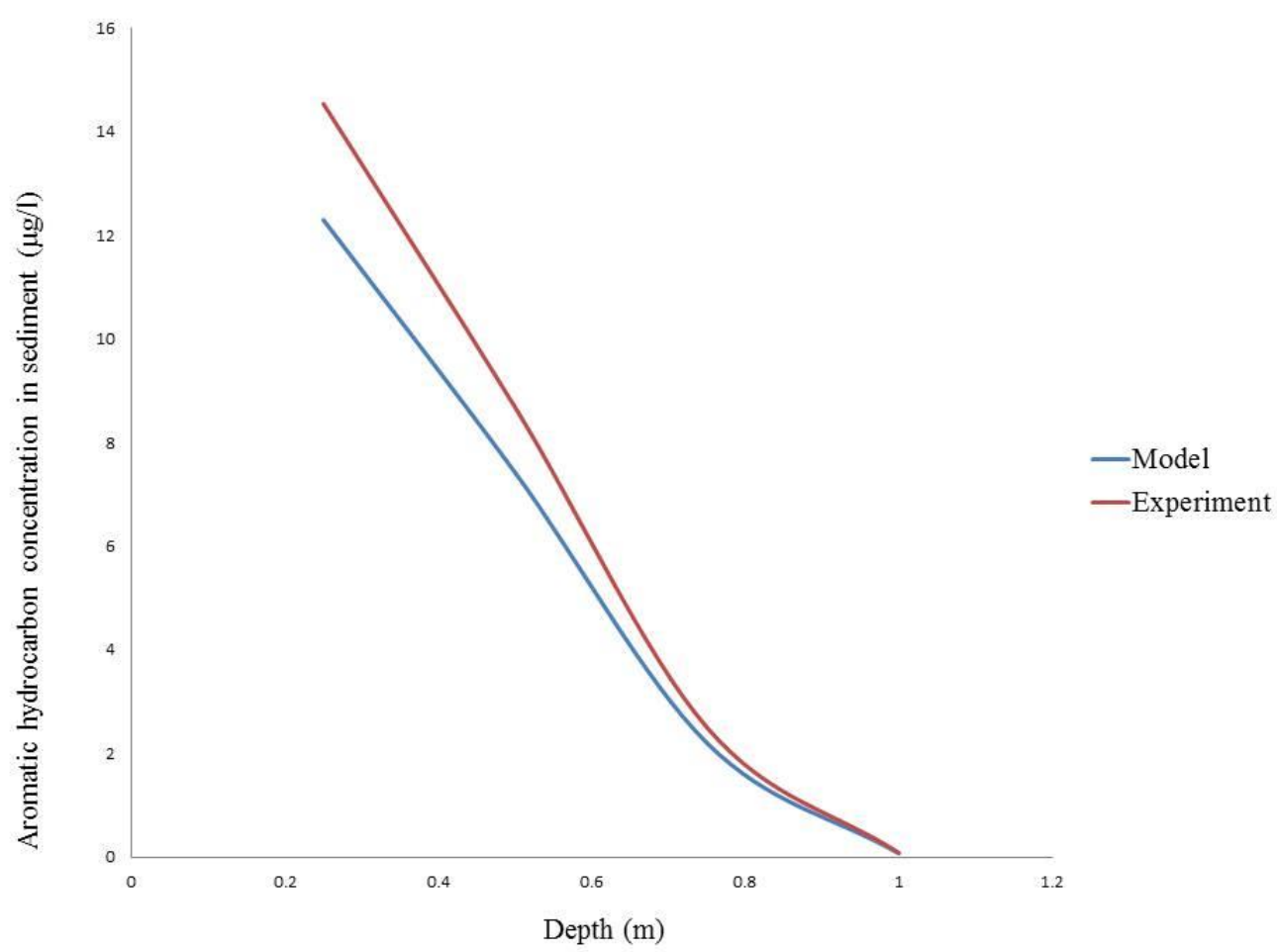

Figure 10. Total aromatic hydrocarbon transport by sediment adsorption for varying depth and fixed time of one month for experiment and model

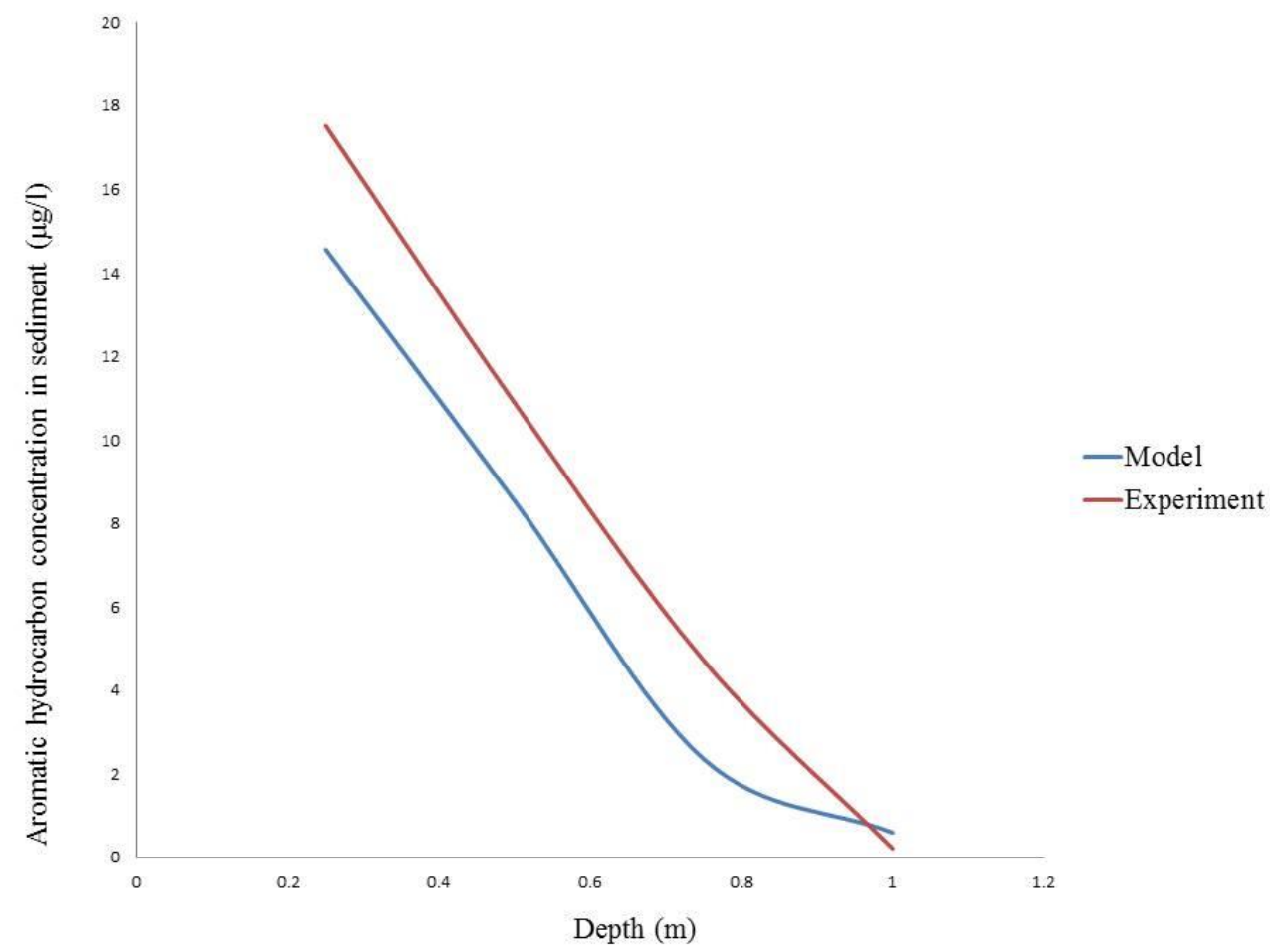

Figure 11. Total aromatic hydrocarbon transport by sediment adsorption for varying depth and fixed time of two months for experiment and model 


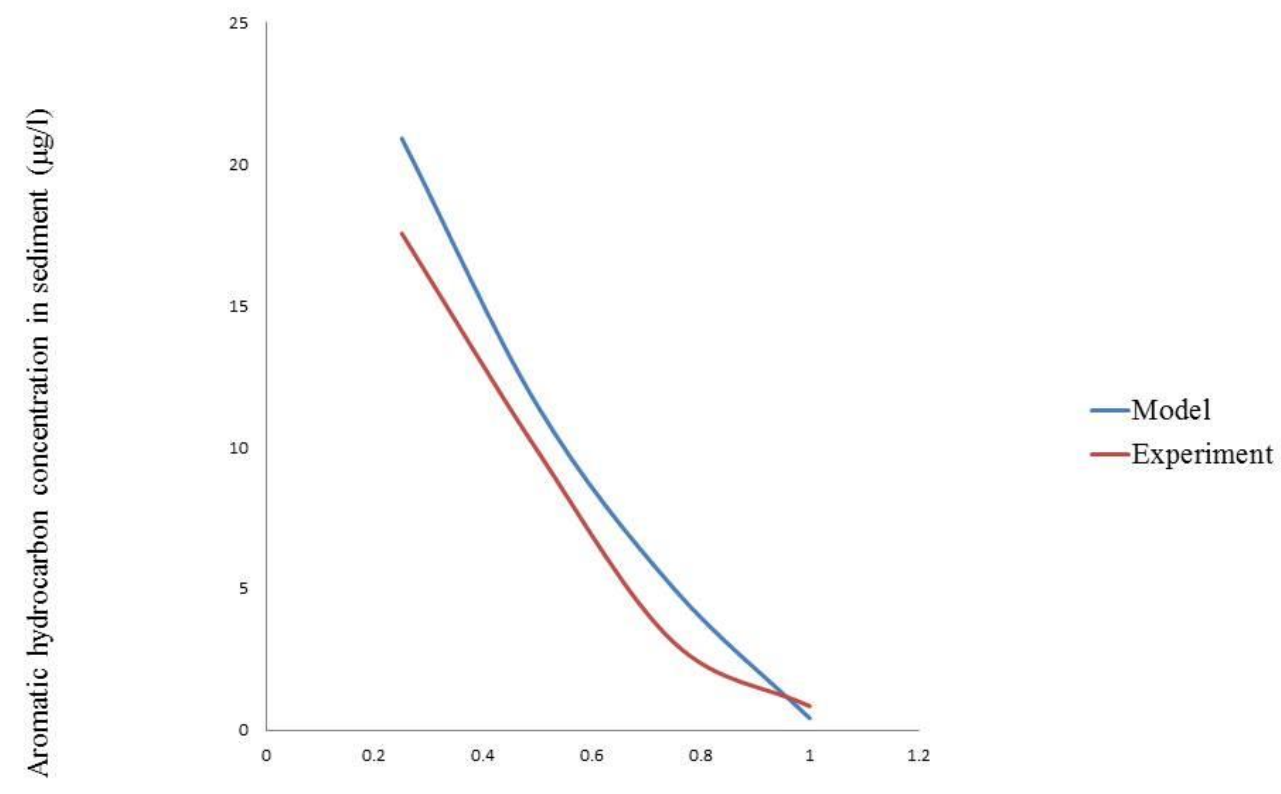

Depth (m)

Figure 12. Aromatic hydrocarbon transport by sediment adsorption for varying depth and fixed time of three months for experiment and model

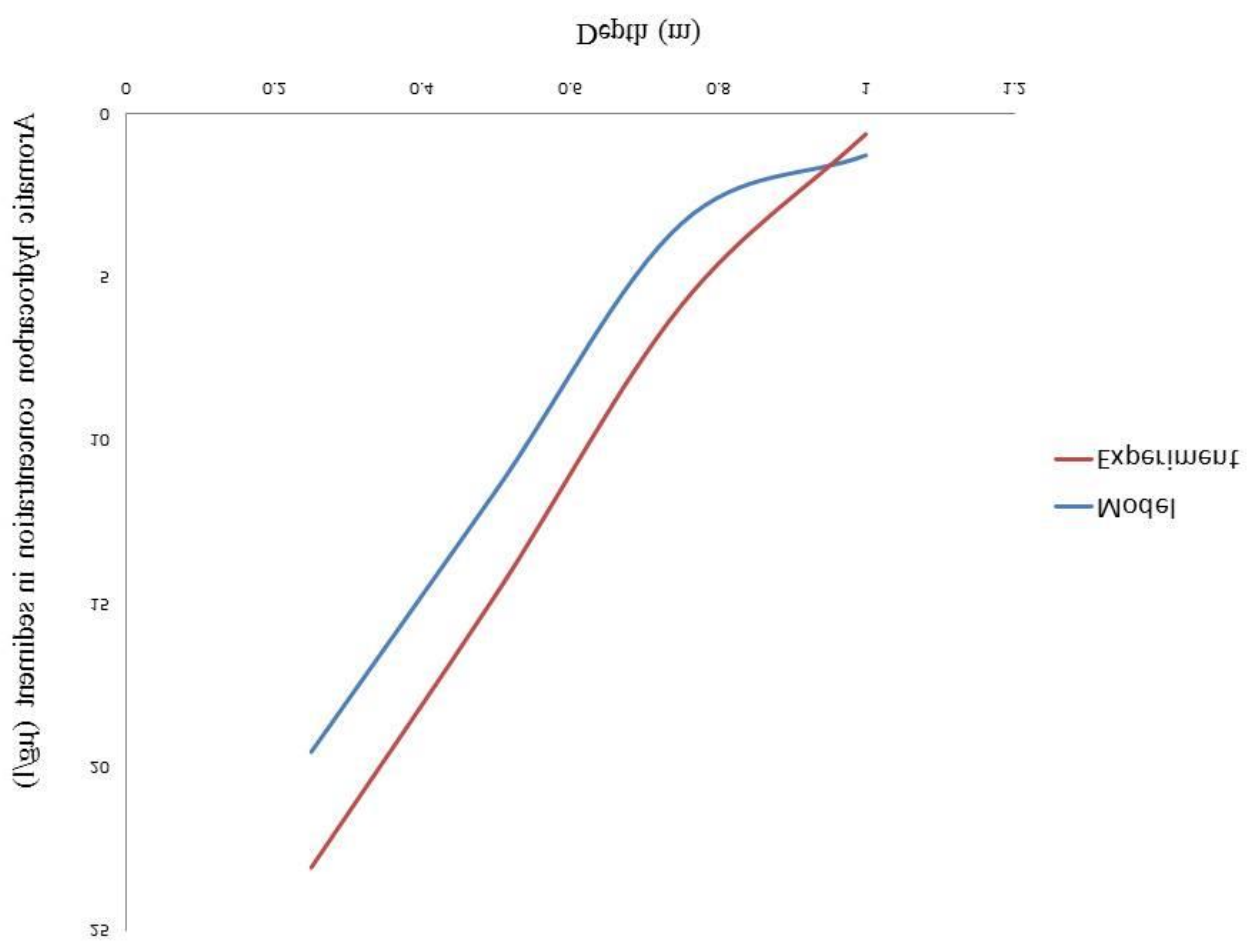

Figure 13. Aromatic hydrocarbon transport by sediment adsorption for varying depth and fixed time of four months for experiment and model 


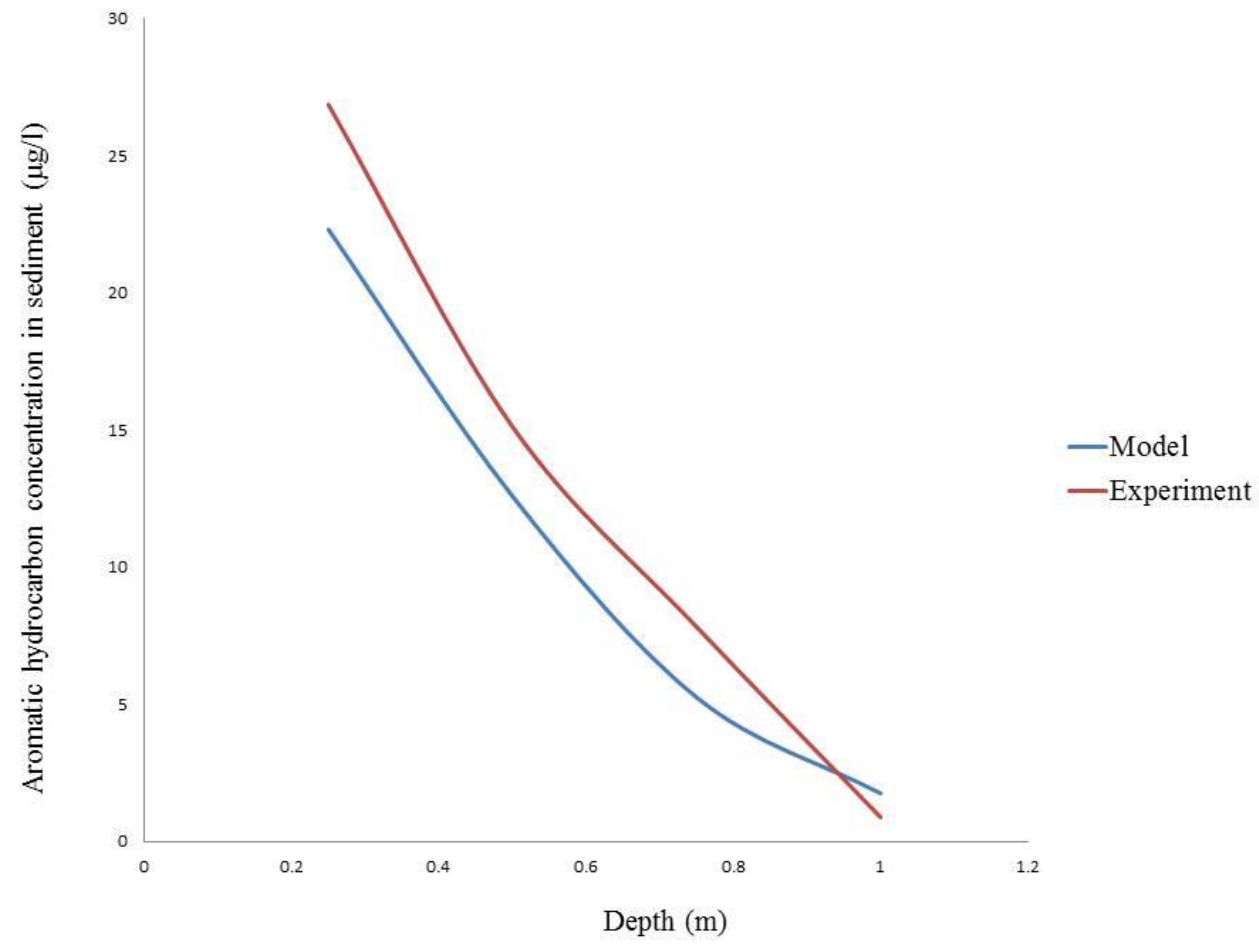

Figure 14. Aromatic hydrocarbon transport by sediment adsorption for varying depth and fixed time of five months for experiment and model

Figures 10 to 14 show the plots for aromatic hydrocarbon transport by suspended sediments from top to bottom of the water column for the experimental and predicted results. As was highlighted in the case of aliphatics above, the plots from month one to five (others not shown) at depth $0.25 \mathrm{~m}$ to $1.0 \mathrm{~m}$ show a good reflection of the experimental plots by the model plots. There was basically no case of remarkable departure of the curves. Also, the $\mathrm{R}^{2}$ values calculated for aromatics hydrocarbon transported by suspended sediments using the model responses as well as the experimental results were $0.99,0.97,0.94$ and 0.98 for 0.25 , $0.5 \mathrm{~m}$, $0.75 \mathrm{~m}$ and $1.0 \mathrm{~m}$ respectively. These imply that the model developed has the capacity to give a good prediction of the aromatic hydrocarbon concentration occasioned by adsorption onto suspended sediment and transported along the water column. Unlike the case of the aliphatic hydrocarbons with relatively lower $\mathrm{R}^{2}$ values, those for the aromatics suggest that the conditions and assumptions adopted better fit for aromatics possibly than aliphatics. It is even more encouraging that the models developed are able predict aromatic hydrocarbon transport relatively well because environmental research attention and focus are more on aromatics than on aliphatics considering the potential of aromatics to cause more harm to both the environment and life therein (Abowei, 1996; Akpofure et al., 2000).

\section{CONCLUSION}

The relatively low research attention accorded to stagnant water bodies of the mangrove swamps particularly in parts of the Nigerian Niger Delta have led to poor understanding of the transport mechanisms of hydrocarbons in such water bodies with resultant poor management of oil spill cases in this area. This led to the development of a predictive model using basic transport and mass transfer equations for quantifying petroleum hydrocarbon pseudo components and here applied to aliphatics and aromatics transported through water by sediment adsorption from depth to depth down the water column. The models developed were then evaluated for fitness using data collected from a simulated mangrove spill site. The result show that the models are adequate and sufficiently robust to predict the aliphatic concentration in water and sediments from depth to depth of a stagnant water column in a mangrove swamp.

\section{NOMENCLATURE}

$\begin{array}{ll}\frac{\partial(\rho \psi)}{\delta t} & \text { - Change in concentration with respect to time (Transient term) } \\ \nabla .(\rho v \Psi) & \text { - Convective transport term } \\ \nabla . J & \text { - Diffusive transport term } \\ \Phi & \text { - Source term } \\ \mathbf{v} & \text { - Fluid velocity }\end{array}$




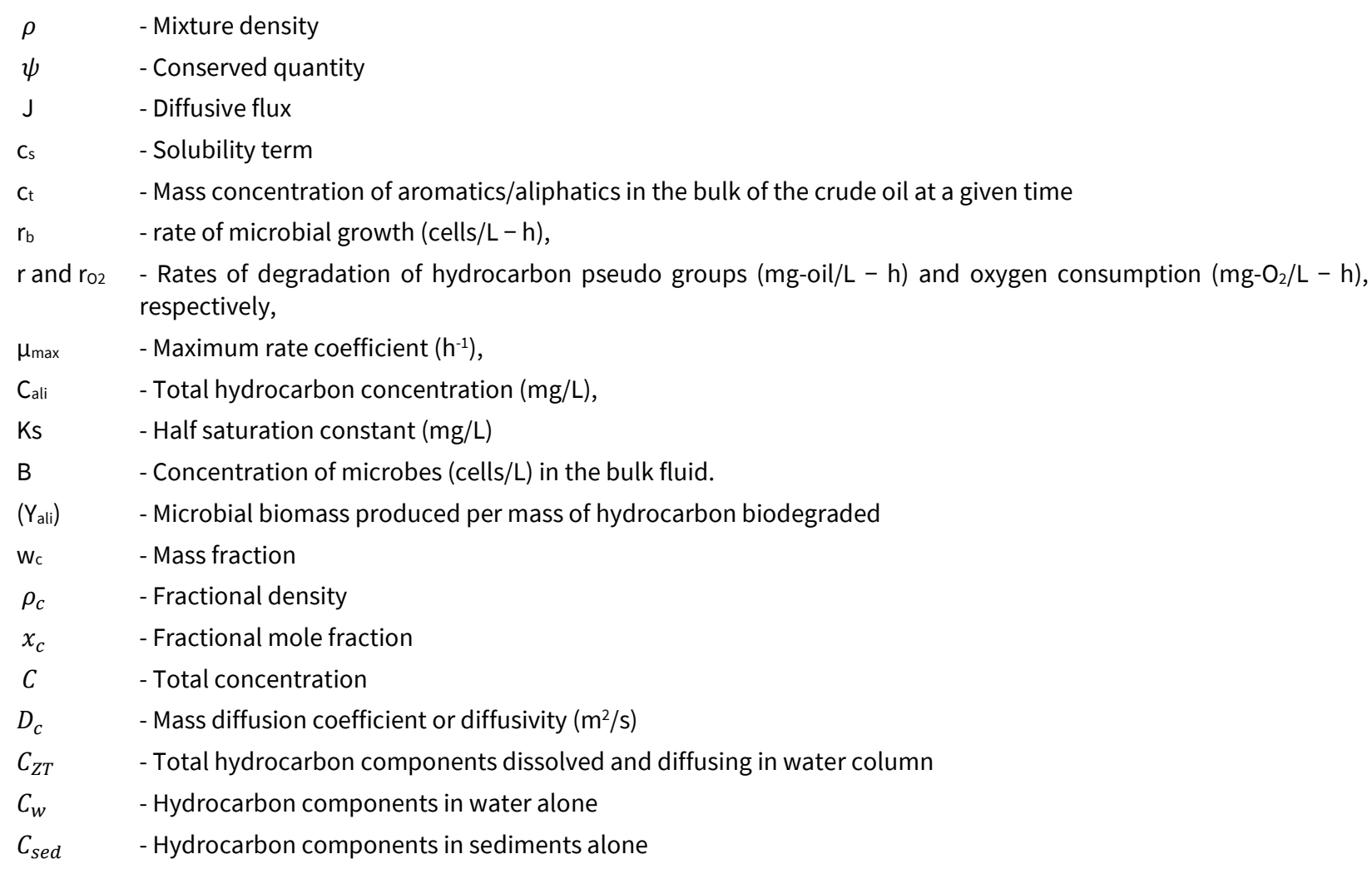

\section{STATEMENT OF NOVELTY}

Models for predicting the vertical transport of dissolved petroleum hydrocarbon components (not whole oil) by suspended sediments after an oil spill in non-turbulent water bodies as found in parts of Nigerian Niger-Delta have been developed. This is the first practical attempt to model transport of spilled oil categorized into its components in such environment with emphasis on the role of suspended sediment without wave action.

\section{REFERENCES}

Abowei, M. F. N. (1996). Prediction and consequences of petroleum spills into the Nigerian aquatic environment in the year 2000. International Journal of Environment and Pollution, 6(23), 306-321.

Akpofure, E. A., Efere, M. L. and Ayawei, P. (2000). Oil spillage in Nigeria's Niger Delta; Integrated grass-root post impact assessment of acute damaging effects of continuous oil spills in the Niger Delta, Urhobo historical Society, 2000. Available at: www.waado.org/Environment/PetrolPolution/OilSpills/OilSpillsImpact

Boufadel, M., Liu, R., Zhao, L., Lu, Y., Özgökmen, T., Nedwed, T. and Lee, K. (2020). Transport of oil droplets in the upper ocean: impact of the eddy diffusivity. Journal of geophysical research, 125(2), 21. https://doi.org/10.1029/2019JC015727

Bragg, J. R. and Owen, E. H. (1995). Shoreline cleansing by interactions between oil and fine mineral particles. In Proceedings of 1995 international oil spill Conference, 1995, Washington D.C., 219-227. https://doi.org/10.7901/2169-3358-1995-1-219

Chao, X., Shankar, N. J. and Cheong, H. F. (2001). Two -and three- dimensional oil spill model for coastal waters. Ocean Engineering, 28, 1557-1573. https://doi.org/10.1016/S0029-8018(01)00027-0

Garcia-Martinez, R. and Flores-Tovar, H. (1999). Computer Modeling of Oil Spill Trajectories with a high Accuracy Method. Spill Science and Technology Bulletin, 5(5/6), 323-330. https://doi.org/10.1016/S1353-2561(99)00077-8

Giwa, A. and Jimoh, A. (2010). Development of models for the spreading of crude oil. AU.J.T, 14(1), 66-71.

Imanian, H., Kolahdoozan, M. and Zarrati, A. R. (2017). vertical dispersion in oil spill fate and transport models. Journal of hydrosciences and environment, 1(2), 21-33.

Jimoh, A. and Alhassan, M. (2006). Modelling and simulation of crude oil dispersion. Leonardo Electronic Journal of practices and Technologies, 4(8), 17-18

Le Floch, S., Guyomarch, J., Merlin, F. X., Stoffyn-Egli, P., Dixon, J. and Lee, K. (2002). The influence of salinity on oil-mineral aggregate formation. Spill Science and Technology Bulletin, 8(1), 65-71. https://doi.org/10.1016/S1353-2561(02)00124-X

Li, D., Tang, X., Li, Y., Wang, X. and Zhang, H. (2018). Mathematical modeling of marine oil spills in the luanjiakou district, near the port of Yantai. Discrete Dynamics in Nature and Society, 2018, 3-6. https://doi.org/10.1155/2018/2736102 
Lonin, S. A. (1999). Lagrangian Model for Oil Spill Diffusion at Sea. Spill Science and Technology Bulletin, 5(5/6), 331-336. https://doi.org/10.1016/S1353-2561(99)00078-X

Njobuenwu, D. O. (2014). Modeling spreading rate force of petroleum spill on placid aquatic medium. Journal of Science and technology research, 3(3), 48-52.

Njobuenwu, D. O. and Abowei, M. F. N. (2008). Spreading of oil spill on placid aquatic medium. Leonardo Journal of Sciences, 7(12), $11-24$.

Odisu, T. (2020). Modeling of oil spill in non -turbulent water of the Niger Delta region of Nigeria (Ph.D Thesis), Department of Chemical Engineering, University of Benin, Nigeria (in preparation), 8-13.

Odisu, T., Okieimen, C. O. and Ogbeide, S. E. (2020). Post Oil Spill Petroleum Hydrocarbon Components Transport and Evaluation in Parts of Southern Niger Delta of Nigeria: A Case of Hydrocarbon Component Transport through Non-Turbulent Water. European Journal of Sustainable Development Research, 4(1), 2-3.

Owens, E. H. and Lee, K. (2003). Interaction of oil and mineral fines on shorelines: Review and assessment. Marine Pollution Bulletin, 47(9-112), 397-405. https://doi.org/10.1016/S0025-326X(03)00209-1

Owens, E. H., Reimer, P. D., Lamarche, A., Marchant, S. D. and O’Brien, D. K. (2003). Pre-Spill shoreline mapping in Prince William Sound, Alaska. In Proceedings of the twenty-sixth Artic and marine oil spill program (AMOP) Technical Seminar, June 10-12, 2003, Victoria, British Columbia, Ottawa, ON, Canada: Canada Environment, 233-251.

Page, C. A., Bonner, J. S., Sumner, P. L., McDonald, T. J., Autenrieth, R. L. and Fuller, C. B. (2000). Behaviour of chemically-dispersed oil and a whole oil on a near-shore environment. Water Research, 34, 2507-2516. https://doi.org/10.1016/S0043-1354(99)00398$X$

Röhrs, J., Dagestad, K.-F., Asbjørnsen, H., Nordam, T., Skancke, J., Jones, C. E. and Brekke, C. (2018). The effect of vertical mixing on the horizontal drift of oil spills. Ocean Science, 14, 1581-1601. https://doi.org/10.5194/os-14-1581-2018

Röhrs, J., Dagestad, K.-F., Asbjørnsen, H., Nordam, T., Skancke, J., Jones, C. E. and Brekke, C. (2019). Vertical mixing and horizontal drift of oil spills: simulations with the open source oil spill model OpenOil. Geophysical Research Abstracts, $21,4833$.

Susu, A. A., Abowei M. F. N. and Onyeme, J. O. (1997). Oil spills in marine environment. CJC press Ltd Lagos, Nigeria.

Tkalich, P. (2006). A CFD solution of oil spill problems. Environmental Modeling and Software, 21, $271-282$. https://doi.org/10.1016/j.envsoft.2004.04.024

Vilcaez, J., Li, L. and Hubbard, S. S. (2013). A new model for biodegradation kinetics of oil droplets: Application to the deep water horizon oil spill in the Gulf of Mexico. Geochemical Transactions, 14(1), 4. https://doi.org/10.1186/1467-4866-14-4

Wang, S. D., Shem, Y. M. and Zhang, Y. A. (2005). Two dimensional numerical simulation for transport and fate of oil spills in the seas. Ocean Engineering, 32, 1556-1571. https://doi.org/10.1016/j.oceaneng.2004.12.010 